\title{
Karakterisering van Grubbs-tipe-prekatalisatore met behulp van kernmagnetieseresonansiespektrometrie
}

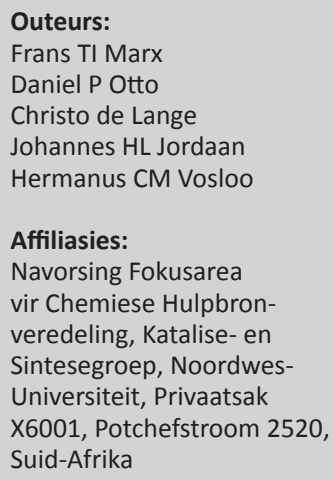

Korresponderende outeur: Dr Johan Jordaan,

Hoe om hierdie artikel aan te haal:

Frans TI Marx, Daniel P Otto, Christo de Lange, Johannes HL Jordaan, Hermanus CM Vosloo, Karakterisering van Grubbstipe-prekatalisatore met behulp van kernmagnetieseresonansiespektrometrie, Suid-Afrikaanse Tydskrif vir Natuurwetenskap en Tegnologie 38(1) (2019). https://doi.org/10.36303/ SATNT.2019.38.1.686

Kopiereg: (C) 2019. Authors. Licensee: Die SuidAfrikaanse Akademie vir Wetenskap en Kuns. Hierdie werk is onder die Creative Commons Attribution License gelisensieer.
Sedert die ontdekking van die ruteniumbevattende prekatalisatore, Grubbs 1 (1) en Grubbs 2 (2), is 'n toename in die ontwikkeling van soortgelyke prekatalisatore getoon. Daar is egter nie met die karakterisering van die prekatalisatore met behulp van kernmagnetieseresonansiespektrometrie (KMR) tred gehou nie. Die gerapporteerde KMRanalises en -karakterisering is meestal tot ${ }^{1} \mathrm{H}_{-},{ }^{31} \mathrm{P}-$, COSY-analise beperk met seldsame vermelde ${ }^{13} \mathrm{C}$-analise. Die hoë natuurlike isotoopvoorkoms van ${ }^{1} \mathrm{H}$ - en ${ }^{31} \mathrm{P}$-kerne, $99.98 \%$ en $100 \%$ onderskeidelik, is 'n bydraende faktor tot die vinnige en eenvoudige opname van hierdie spektra. Die leemte in literatuurdata en- opnameparameterstelle aangaande ${ }^{13} \mathrm{C}$-KMR-analise, word aan die lae natuurlike isotoopvoorkoms van ${ }^{13} \mathrm{C}$-kerne $(1.10 \%)$ en die ingeperkte stabiliteit van die katalisatore in oplossing toegeskryf.

In hierdie ondersoek is prekatalisator 1 gebruik om 'n KMR-parameterstel te ontwikkel. Daarna is twee verdere kommersiële Grubbs-tipe-prekatalisatore, 2 en 3, met behulp van hierdie KMR-parameterstel geanaliseer. Die KMR-spektra is weens die lang opnametyd en die onstabiliteit van die prekatalisatore in oplossing in drie stappe opgeneem. Eerstens, is ${ }^{1} \mathrm{H}-$, COSY-, HSQC- en HMBC-spektra opgeneem, wat altesaam vier ure geduur het. Tweedens, is DEPT135-spektra opgeneem, wat drie ure in beslag geneem het. Laastens is die ${ }^{13} \mathrm{C}$-spektra opgeneem waarvoor 7 ure in beslag geneem is.

Die KMR-parameterstel wat vanaf die kommersiële prekatalisatore afgelei is, is gevolglik aangewend om ses verdere gesintetiseerde, nie-kommersiële Grubbs-tipeprekatalisatore, 4 tot $\mathbf{9}$, gedeeltelik te karakteriseer. Deur die voorkoms van oorvleuelende pieke in die aromatiese en alifatiese gebiede is die spektrumresolusie verlaag. Gevolglik is die volledige karakterisering nie moontlik gemaak nie.

Sleutelwoorde: Grubbs-tipe-prekatalisator, kernmagnetieseresonansiespektrometrie, KMRparameterstel, KMR-karakterisering

Characterisation of Grubbs-type precatalysts with nuclear magnetic resonance spectrometry: Since the discovery of the ruthenium-based precatalysts (1) and (2), an increase in the development of similar precatalysts has been observed. However, the nuclear magnetic resonance (NMR) spectroscopic characterization of these precatalysts could not parallel the development in the field. The NMR analyses and characterisation, reported in the literature, is limited to ${ }^{1} \mathrm{H},{ }^{31} \mathrm{P}, \mathrm{COSY}$ and in rare case ${ }^{13} \mathrm{C}$ analyses. The ease and short duration of the spectral recording of ${ }^{1} \mathrm{H}$ and ${ }^{31} \mathrm{P}$ nuclei are ascribed to their high, natural isotope abundance of $99.98 \%$ and $100 \%$ respectively. The lack of reported ${ }^{13} \mathrm{C}$ NMR data of these precatalysts is attributed to the low natural isotope abundance of ${ }^{13} \mathrm{C}$-nuclei $(1.10 \%)$ and the observed instability of the catalysts in solution. In this investigation, precatalyst 1 was employed to determine a NMR parameter set, after which two additional commercial Grubbs-type precatalysts, 2 and 3, were analysed with the deduced NMR parameter set. The obtained peak shift values were compared with literature reported values. The excessive recording time and the instability of the precatalysts in solution necessitated recording the NMR spectra in three steps. Firstly, the ${ }^{1} \mathrm{H}, \mathrm{COSY}, \mathrm{HSQC}$ and HMBC spectra were recorded over a total duration of four hours. Secondly, DEPT135-spectra were recorded, over a period of three hours. Lastly, the ${ }^{13} \mathrm{C}$-spectra were recorded over seven hours.

Subsequently, the developed NMR parameter set was applied to partially elucidate the structure of six synthesised, non-commercial Grubbs-type precatalysts, 4 to 9 . The overlapping peaks, in the aromatic and aliphatic regions of the spectra, decreased the resolution and consequently hampered total structure elucidation.

\section{Inleiding}

KMR-spektrometrie is met die ondersoek van molekulêre strukture gemoeid. Dié spektrometriese tegniek berus op die wisselwerking tussen 'n versameling van kerne en 'n afwisselende elektromagnetiese veld wat deur radiofrekwensiebestraling teweeggebring word (Macomber, 1997). Die wisselwerking tussen kerne en die aangebringde magneetveld wek 
die kerne op tot 'n hoër energievlak as in die onopgewekte toestand. Nadat die radiofrekwensiebestraling opgehef word, keer alle kerne tot hulle onopgewekte toestand terug. Tydens hierdie ontspanningsproses word die opwekkingenergie weer uitgestraal. Elke kern keer teen sy eie tempo tot die onopgewekte toestand terug. Gevolglik kan hierdie uitstraling vir elke verskillende kern as resonansiesein waargeneem word (Macomber, 1997).

Hierdie analisemetode kan dus tydens die ondersoek van katalitiese reaksies waardevolle inligting rakende die katalisatorstruktuur en meganisme van die reaksie onthul. Die verandering in die katalisator-, substraaten produksamestelling word dus geredelik met behulp van KMR-spektrometrie gemoniteer. Hierdie tegniek mag veral in die veld van homogene metatese, spesifiek olefienmetatese, beduidend wees.

Olefienmetatese beskryf reaksies waartydens die bindings in die middel van die twee alkeenkoolstowwe gesplyt word. Gevolglik vind 'n posisieverwisseling van atome tussen die twee gevormde alkeenmolekules plaas om twee nuwe alkene te lewer (Grey, 2000). Die Grubbs-tipeprekatalisatore word gebruik in die olefienmetatesereaksie wat vir die eerste keer in die 1950s waargeneem is (Grey, 2000, Rouhi, 2005). Verbeteringe in die aktivering van die metaalkarbeen het daartoe gelei dat die reaksie meer aftrek in navorsing begin geniet het (Grey, 2000, Rouhi, 2005). Grubbs-tipe-prekatalisatore het die gebruik van olefienmetatese vir chemici by uitstek vergemaklik. Hierdie vergemakliking spruit uit die gerief waarmee die prekatalisatore tydens laboratoriumskaalondersoeke hanteer kan word (Rouhi, 2005).

Van der Schaaf et al. (1999) het die stabiliteit van die eerste en tweede generasie Grubbs-tipe-prekatalisatore ( 1 en 2 in Figuur 1) by verhoogde temperature in oplossing verbeter deur 'n chloor en 'n $\mathrm{PCy}_{3}$-ligand met 'n piridinielalkoholatoligand te vervang. Die piridinielalkoholatoligand stabiliseer die rustoestand van die Grubbs-tipe-prekatalisator en by verhoogde temperature word 'n oopkoördinasiesetel gelewer (Ledoux, 2007). Die piridinielalkoholatoafgeleide prekatalisatore van 1 en $\mathbf{2}$ ( 4 tot 9 in Figuur 1) is tydens die huidige ondersoek volgens die metode van Denk et al. (2002) gesintetiseer. KMR-spektrometrie is tot op hede nie ten volle benut om die piekverskuiwingswaardes van die Grubbs-tipeprekatalisatore, veral die voorbeelde in Figuur 1, ten volle te bepaal nie. Die maklikste analiseringmetodes soos byvoorbeeld ${ }^{1} \mathrm{H}-,{ }^{31} \mathrm{P}$ - en COSY-analises en by uitsondering ${ }^{13} \mathrm{C}$-analises is in die literatuur beskryf (Gallagher et al., 2008, Huijsmans, 2009, Jordaan, 2007, Louie en Grubbs, 2002, Schachner et al., 2011, Schwab et al., 1996). 'n Moontlike verklaring vir hierdie verskynsel is dat hierdie KMRkarakteriseringsmetode lank neem en duur is. Tydens hierdie ondersoek is vasgestel dat ongeveer 17 ure per prekatalisator benodig word om die reeks KMR-spektra op te neem. Eerstens is ${ }^{1} \mathrm{H}-$, COSY-, HSQC- en HMBC-spektra opgeneem, wat altesaam vier ure geduur het. Tweedens, is DEPT135-spektra opgeneem wat drie ure in beslag geneem het. Laastens is die ${ }^{13} \mathrm{C}$-spektra oor sewe ure opgeneem. Die Grubbs-tipe-prekatalisatore het 'n kort leeftyd in oplossing en dit beteken dat ' $n$ enkele KMR-monster nie vir al die analises gebruik kan word nie. Nuwe monsters moet gereeld tydens die KMR-analise berei word waardeur die opname van die spektra verder bemoeilik is. Tydens hierdie ondersoek is drie kommersiële prekatalisatore, $\mathbf{1}$ tot 3, gebruik om 'n KMR-parameterstel saam te stel. Die doel was spesifiek om 'n verstekwaardeparameterstel af te lei wat toekomstige ondersoeke van soortegelyke prekatalisatore sou vergemaklik. Die ooreenkoms tussen die piekverskuiwingswaardes van $\mathbf{1}$ tot $\mathbf{3}$, in hierdie ondersoek bepaal, met literatuurwaardes, bekragtig die parameterstel se bruikbaarheid. Vervolgens is ses nie-kommersiële Grubbs-tipe-prekatalisatore, 4 tot 9, gesintetiseer. Voorts is die saamgestelde KMR-parameterstel gebruik om die struktuur van hierdie prekatalisatore te ondersoek. Die bepaalde piekverskuiwingswaardes van 4 tot 9 het goeie ooreenkomste met die literatuurwaardes vertoon. Daar is bevind dat een KMR-parameterstel onvoldoende is om die struktuur van al die moontlike Grubbs-tipe-prekatalisatore ten volle te bepaal. Verdere verfyning van die parameterstel sal in toekomstige ondersoeke uitgevoer word om die piekverskuiwingswaardes van die katalisatore te bepaal. Die meganistiese verloop van die metatesereaksies sou moontlik ook hierdeur beter gemoniteer kan word.

\section{Materiaal en metodes Materiaal}

n-Butiellitium, 2-broompiridien, bensofenoon, 2-metielbensofenoon, Grubbs 1 en 2, sikloheksanoon (Sigma-Aldrich) en dieprekatalisator,3, watinSigma-Aldrichseruteniummetatese stel (687944-1KT) voorkom, is gebruik soos ontvang is. Tetrahidrofuraan (Sigma-Aldrich) en diëtieleter (Labchem) is onder 'n stikstoflaag (Afrox) oor natrium (Riedel-de Haën) en bensofenoon (Merck) gedistilleer. Tolueen en n-pentaan (beide Sigma-Aldrich) is oor kalsiumhidried (Aldrich) onder 'n stikstoflaag (Afrox) gedistilleer.

\section{Sintese van die piridinielalkoholatoligande en dienooreenkomstige Grubbs-tipe-prekatalisatore}

'n Kort beskrywing van die algemene gerapporteerde sinteseprosedures vir die piridinielalkoholatoligande (Herrmann et al., 1997), piridinielalkoholatolitiumsoute (Herrmann et al., 2000) en die Grubbs-tipe-prekatalisatore 4 tot 9 (Huijsmans, 2009, Jordaan, 2007), word in Figuur 2 uitgebeeld. Die volledige piekverskuiwingswaardetoekennings van die onderskeie verbindings kan in die bylaag gevind word.

\section{KMR-buisvoorbereiding}

Om skade aan die pylstif te voorkom, is dit belangrik om die KMR-buise deeglik voor gebruik vir krapmerke, krake en onoplosbare stowwe in of op die buise te ondersoek. 'n Pypskoonmaker en asetoon is gebruik om die buise skoon 


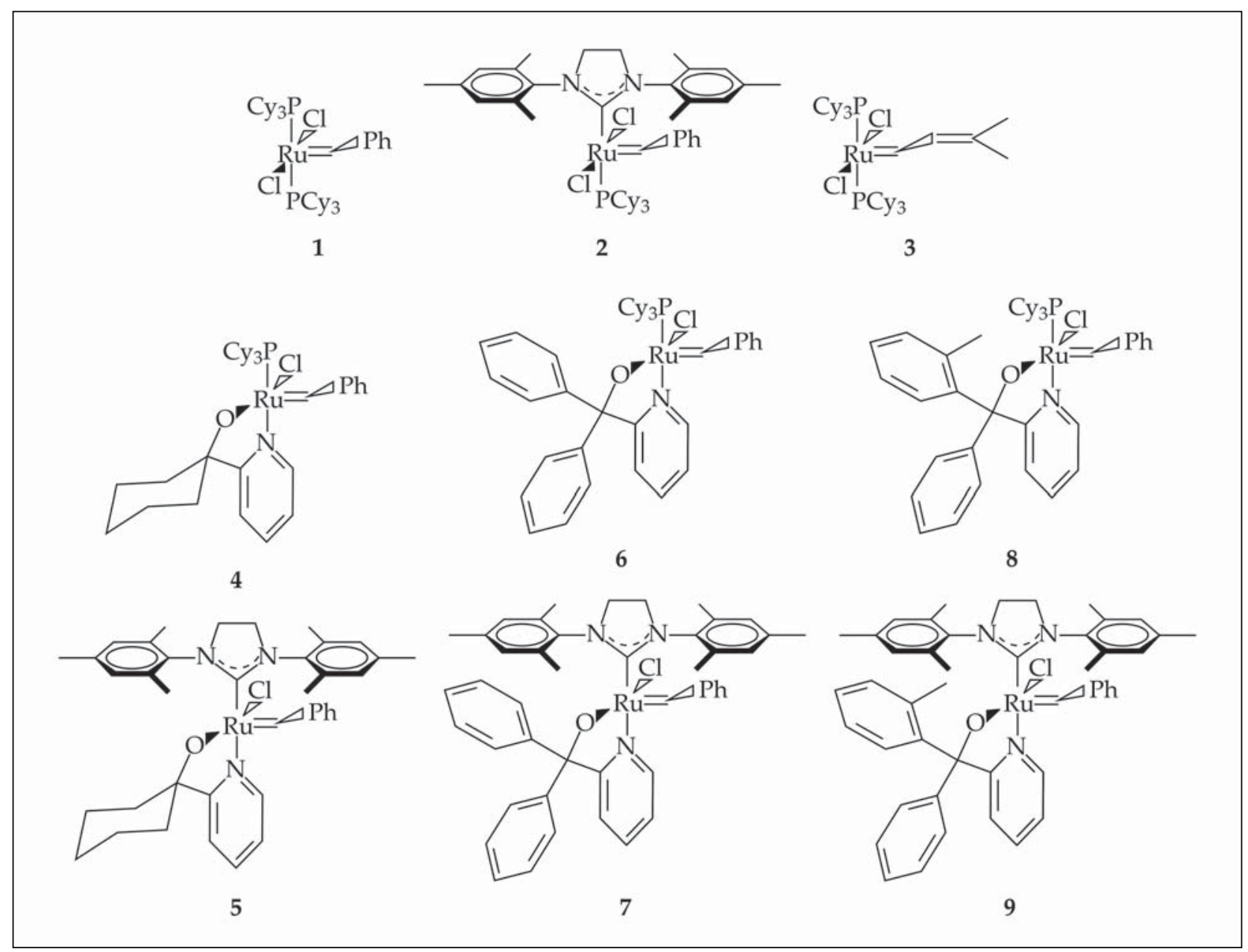

FIGUUR 1: Die drie kommersiële (1 tot $\mathbf{3}$ ) en die ses nie-kommersiële (4 tot $\mathbf{9})$ Grubbs-tipe-prekatalisatore wat met behulp van KMR-spektrometrie tydens hierdie ondersoek gekarakteriseer is $\left(\mathrm{Ph}=\right.$ bensiel, $\left.\mathrm{C}_{6} \mathrm{H}_{5}\right)$.

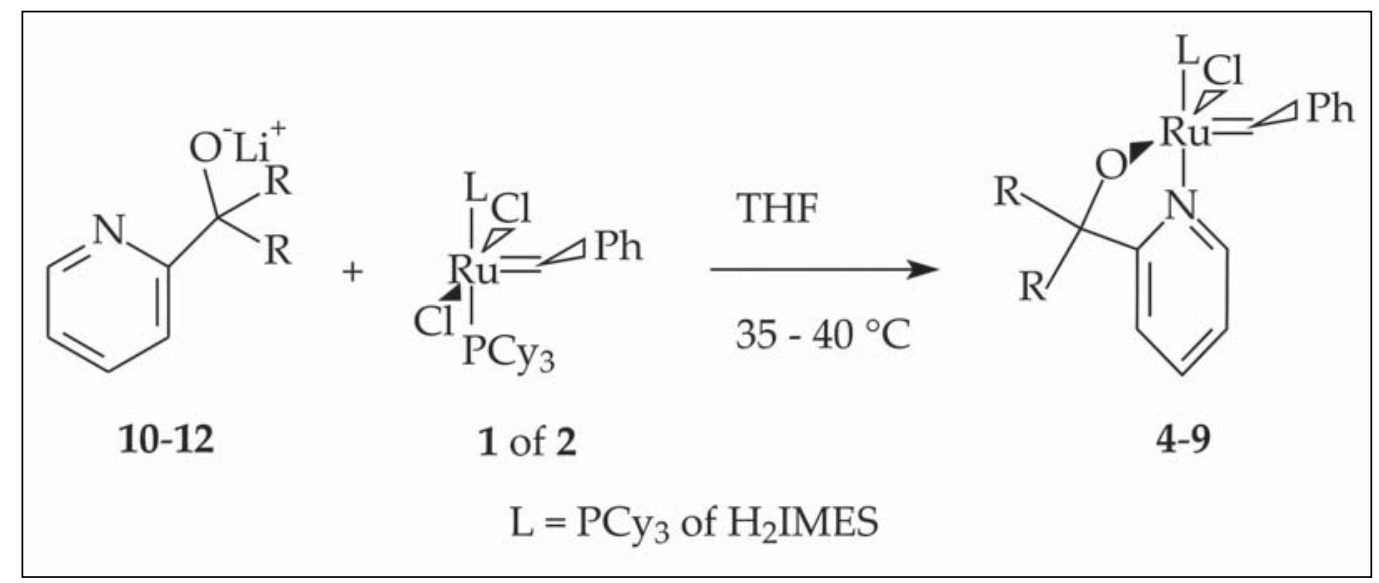

FIGUUR 2: Algemene sinteseprosedure vir die Grubbs-tipe-prekatalisatore $\mathbf{4}$ tot $\mathbf{9}$.

te was, vervolgens is enige oorblywende asetoon met gedeïoniseerde water uit die buis gespoel waarna dit met stikstof droog geblaas is en in 'n desikkator geberg is totdat dit benodig word.

\section{KMR-oplosmiddelvoorbereiding}

Die gedeutereerde oplosmiddel is in 'n Schlenkbuis, kwartweg gevul met geaktiveerde $4 \AA$ molekulêre sifmateriaal, tot ongeveer twee derdes bo die sifmateriaal oorgedra. Die oplosmiddel is gevries deur die Schlenkbuis, met die klep gesluit, in vloeibare stikstof te plaas. Die Schlenkbuis is uit die vloeibare stikstof verwyder en onder vakuum geplaas totdat die eerste druppels oplosmiddel gevorm is. Die Schlenkbuis is vervolgens met argon gespoel totdat die oplosmiddel heeltemal vervloei het. Die vloeibare stikstof vriesdrogingsproses is twee maal herhaal. Die oplosmiddel is oor molekulêre sifmateriaal in 'n desikkator geberg om te verseker dat dit droog en kontaminasievry bly. 
Die gedeutereerde chloroform ${ }^{1} \mathrm{H}$-spektra is vir 'n waterpiek by $1.5 \mathrm{dpm}$ ondersoek om te bevestig dat die chloroform watervry is. Die oplosmiddel is elke keer voor gebruik met stikstof ontgas om suurstof te verwyder.

\section{KMR-monstervoorbereiding}

Die KMR-buis is voor gebruik vir 10 minute met argon in 'n Schlenkbuis uitgespoel. Alle gasdigte spuite is voor gebruik met argon gespoel. Die prekatalisatormonster (20 $\mathrm{mg}$ ) is in 'n Pasteurpipet met 'n wattepluisie in die voorpunt afgeweeg. Voorts is die monster met $0.5 \mathrm{~mL}$ gedeutereerde oplosmiddel in die KMR-buis oorgedra. Die KMR-buis is, indien nodig, met verdere oplosmiddel tot 'n hoogte van ongeveer vier sentimeter opgevul waarna dit met ' $n$ prop en Parafilm ${ }^{\circledR}$ geseël is. Die KMR-buis is vervolgens met gedeutereerde chloroform afgevee om te verseker dat die buis skoon is. Die plastiekturbine, waarmee die KMR-buis in die instrument geplaas word, is ook afgevee om te verseker dat dit stofvry is. Die plastiekturbine is op die dieptebepaler geplaas en die KMR-buis is daarin tot op die bodem van die dieptebepaler geskuif. Die dieptebepaler verseker dat die KMR-buis nie die maksimale diepte in die pylstif oorskry en dit beskadig nie. Dit verseker ook dat die middel van die monsteroplossing in die korrekte posisie in die pylstif geplaas word. Die KMR-buis is vanuit die dieptebepaler verwyder en weer skoongevee om te verseker dat geen kontaminante na die pylstif oorgedra word nie.

\section{KMR-parameterinstellings}

Die onderskeie KMR-parameters is met behulp van die Topspin-rekenaarprogrammatuur verstel voordat die opnames uitgevoer is. Tabel 1 vat die verstellings saam.

\section{Analises}

\section{Gaschromatografie/massaspektrometrie (GC/MS)}

Die GC/MS-analises is hoofsaaklik gebruik om die suiwerheid van die gesintetiseerde piridinielalkoholatoligande te bepaal. ' $n$ Agilent $6890 \mathrm{~N}$ GC toegerus met 'n HP-5 $30 \mathrm{~m} \times 320 \mu \mathrm{m} \times 0.25 \mu \mathrm{m}$ filmdikte kapillêre kolom is aan 'n Agilent 5973 massaselektiewedetektor (MSD) gekoppel. Die heliumdraergas is teen 'n vloeitempo van 1.5 $\mathrm{mL} / \mathrm{min}$ ingestel. Die waardes vir die onderskeie parameters is soos volg ingestel: inspuitingsverdelingsverhouding: 50:1, verdelingsvloei: $74.9 \mathrm{~mL} / \mathrm{min}$, inlaattemperatuur: $250^{\circ} \mathrm{C}$, en spuitvolume $0.2 \mu \mathrm{L}$. Die oondverhittingssiklus is soos volg opgestel: $120^{\circ} \mathrm{C}$, handhaaf vir 2 minute, oondverhitting: 120 tot $290{ }^{\circ} \mathrm{C}$ teen $10^{\circ} \mathrm{C} / \mathrm{min}$ en handhaaf vir $5 \mathrm{~min}$ teen $290^{\circ} \mathrm{C}$.

\section{Infrarooispektrometrie (IR)}

IR-spektra is met 'n Bruker ALPHA-P ATR-IR (uitgedoofde totale refleksie infrarooispektrometrie) opgeneem. Die monsters is direk op die ATR-kristal vir opname geplaas. Opus, weergawe 6.5 rekenaarprogrammatuur is vir analise van die spektra gebruik.

\section{Smeltpunte}

Die smeltpunte van die piridinielalkoholatoligande is met 'n Buchi B-540 gemeet.

\section{Kernmagnetieseresonansspektrometrie (KMR)}

Die KMR-spektra is met behulp van 'n Bruker Ultrashield Plus 600 Avance III-spektrometer toegerus met'n BBO-pylstif (direkte breëbandwaarneming, BBO) of met 'n indirekte TBI-pylstif (drievoudige, indirekte breëbandwaarneming, TBI) opgeneem. Die frekwensies van die verskillende KMR-spektra opnames is soos volg: ${ }^{1} \mathrm{H}-\mathrm{KMR}(600 \mathrm{MHz})$, ${ }^{13} \mathrm{C}-\mathrm{KMR}$ (150 MHz), ${ }^{31} \mathrm{P}-\mathrm{KMR}$ (242 MHz), DEPT135 (150 $\mathrm{MHz})$, COSY (600 MHz) HSQC en HMBC (600 MHz vir ${ }^{1} \mathrm{H}$-waarneming en $150 \mathrm{MHz}$ vir denkbeeldige ${ }^{13} \mathrm{C}$-spektra). Die spektra is met die Topspin 2.1, opgraderingsvlak (PL) 6, rekenaarprogrammatuur geanaliseer.

\section{Massaspektrometrie (MS)}

Beide atmosferiesedruk chemiese-ionisering (APCI) en elektronsproei-ionisering (ESI) spektra is met behulp van 'n Bruker microTOF-Q II-massaspektrometer opgeneem. Die opnameparameters vir die APCI-analise is soos volg: skanderinggebied: 50 tot $1500 \mathrm{~m} / \mathrm{z}$, ioonpolariteit: positief,

TABEL 1: Die parameters wat in die Topspinprogram verstel is.

\begin{tabular}{ll}
\hline Parameter & Beskrywing \\
\hline PULPROG & Die pulsprogram wat gebruik word. \\
TD & Die tydsdomein (TD) bepaal die aantal roudatapunte wat gebruik word om die vrygeïnduseerde ontspanningskurwe (FID-kurwe) te definieer. Die resolusie van \\
& die spektrum mag deur die aantal roudatapunte beïnvloed word. \\
NS & Die aantal skanderings (NS) is'n heelgetalwaarde waarvan die minimumwaarde deur die pulsprogram gedefinieer word. Die sein-tot-geraasverhouding kan as \\
& funksie van die vierkantswortel van die aantal skanderings verbeter word. \\
d1 & Die ontspanningsvertragingstydperk (d1) tussen skanderings vind aan die begin van die pulsvolgreeks plaas. Dié tydperk mag ' $n$ beduidende invloed op die \\
& piekintensiteit, gevolglik die integrasiewaarde van die pieke, teweegbring (Mainz, 2004). \\
DS & Die aantal skynskanderings ("dummy scans”). Geen seinopname vind gedurende hierdie skanderings plaas nie. Dit is belangrik vir die T1-ontspanningstyd om \\
& plaas te vind asook vir die stabilisering van temperatuur. \\
SW & Die spektraalwydte (SW) in dpm (dele per miljoen) is onafhanklik van die frekwensie van die spektrometer, alhoewel die spektraalwydte in Hz wel verandering \\
& sal toon. \\
AQ & Die tydsduur van' $n$ volledige, enkele opname. \\
O1P & Bepaal die middelpunt van die spektraalwydte in dpm. \\
\hline
\end{tabular}


eindplaatverstelling: $-500 \mathrm{~V}$, botsingsselradiofrekwensie (RF): $100.0 \mathrm{Vpp}$, nebuliseerder: 1.6 bar, droë verwarmer: $200{ }^{\circ} \mathrm{C}$ en droëgas (stikstof) vloeitempo: $8.0 \mathrm{~mL} / \mathrm{min}$.

Die opname parameters vir die ESI-analise is soos volg: skanderinggebied: 50 tot $1500 \mathrm{~m} / \mathrm{z}$, ioonpolariteit: positief, eindplaatverstelling: $-500 \mathrm{~V}$, botsingssel RF: $100.0 \mathrm{Vpp}$, nebuliseerder: 0.4 bar, droë verwarmer: $180{ }^{\circ} \mathrm{C}$ en droëgas (stikstof) vloeitempo: $4.0 \mathrm{~mL} / \mathrm{min}$. Die monsters is voorberei deur $1 \mathrm{mg}$ prekatalisator in $1 \mathrm{~mL}$ chloroform op te los. Vervolgens is $2 \mu \mathrm{L}$ van hierdie oplossing in $998 \mu \mathrm{L}$ chloroform verdun. ' $n$ Monster is uit die verdunning deur middel van 'n direkte infusiepomp na die inlaatanaliseerder vir analise oorgedra.

Matriksgesteunde laserdesorpsie/ionisering vlugtyd MS-analises (matrix assisted laser desorption ionisationtime of flight mass spectrometry, MALDI-TOF-MS) is met behulp van 'n Bruker autoflexTOF/TOF-MS/MS massaspektrometer opgeneem. Die opname parameters vir dieMALDI-TOF-analise is soos volg: laserbestralingstempo: $1000 \mathrm{~Hz}$, aantal bestralings: 600, teikenplaat: growwestaal en spanningspolariteit: positief. Monsters is voorberei deur $1 \mathrm{mg}$ prekatalisator in $1 \mathrm{~mL}$ chloroform op te los. ' $\mathrm{n} 1 \mu \mathrm{L}$ deelvolume is met die trans-2-[3-(4-ters-butielfeniel)-2metiel-2-propenielideen]malonnitriel-matriks, wat oor ' $n$ konsentrasie van $20 \mathrm{mg}$ per $\mathrm{mL}$ beskik, vermeng. Laastens is $1 \mu \mathrm{L}$ van die mengsel op die teikenplaat toegedien en toegelaat om droog te word voordat die teikenplaat in die spektrometer geplaas is.

\section{Resultate en Bespreking Bepaling van die KMR-parameterstel}

Die onderskeie parameterstelle, soos in die onderliggende afdelings uiteengesit is, bied 'n stel verstekwaardes vir die ondersoek van Grubbs-tipe-prekatalisatore. Hierdie opnamemetodes kan tydens toekomstige ondersoeke verder verfyn word indien dié waardes nie die verlangde resolusie tydens die KMR-analise lewer nie. Die afgeleide waardes wat uit hierdie studie volg spreek die leemte in die literatuur soos dit tans ervaar word, gedeeltelik aan. Ten spyte van die leemtes sal dit ' $n$ bydra tot die metateseveld lewer.

\section{${ }^{1} \mathrm{H}$-parameterstel}

Die SW-parameterwaarde is vanaf 1.00 tot $22.97 \mathrm{dpm}$ gevarieer. Die gekose gebied verseker dat die karbeensein $(\mathrm{Ru}=\mathrm{CH})$, wat bo $17 \mathrm{dpm}$ waargeneem word, ingesluit is. Die O1P-parameterwaarde (die middel van die spektrum) is na $10.1 \mathrm{dpm}$ verander om 'n breër standaardspektrum te verkry. Die ${ }^{1} \mathrm{H}$-parameterstel word in Tabel 2 saamgevat.

\section{${ }^{13} \mathrm{C}$-parameterstel}

Die SW-parameterwaarde is vanaf 238.9 na $345.0 \mathrm{dpm}$ verander. Alhoewel die karbeensein in die gebied verwag word, is dit aanvanklik nie waargeneem nie. Schachner et al. (2011) het 'n NS-waarde (aantal skanderings) van 15000 gebruik. Gevolglik is daar op 'n NS-waarde van 15104

\begin{tabular}{ll} 
TABEL 2: & ${ }^{1} \mathrm{H}$-parameterstel. \\
\hline Offset [dpm] $^{\mathrm{a}}$ & 21.58572 \\
Pulprog $^{\mathrm{b}}$ & $\mathrm{zg} 30$ \\
TD & 65536 \\
$\mathrm{~d} 1[\mathrm{~s}]$ & 1.000 \\
NS & 16 \\
DS & 2 \\
SW [dpm] ${ }^{\mathrm{a}}$ & 22.9712 \\
AQ [s] & 2.3768 \\
O1P [dpm] & 10.1 \\
\hline
\end{tabular}

a Hierdie versettingswaarde na die positiewe as bly onveranderd vir alle 2D-analises wat met die ${ }^{1} \mathrm{H}$-kanaal uitgevoer word.

Die pulsprogram stel dat ' $n 30^{\circ}$ puls gebruik word.

skanderings vir hierdie studie besluit. Die groot aantal skanderings het die opnametydsduur van die analise buitensporig verleng. Gevolglik is moontlikhede om die opnametyd te verkort oorweeg. Die instruksie SINO (sein-tot-geraasverhouding) is oor die karbeenseingebied toegepas met behulp van die rekenaarprogrammatuur om die sterkte van die karbeensein te bepaal. Sodra die gekose drempelwaarde van SINO oorskry is, word die dataopname gestaak. Die ontspanningstydwaarde, $\mathrm{d} 1$, is vanaf 1 sekonde na 2 sekondes verstel om 'n SINO-waarde van 3.6 te lewer. Die moontlikheid van ooropwekking is oorweeg en die ontspanningstydperk is na 4 sekondes verleng; 'n SINOwaarde van 3.6 is steeds waargeneem. Gevolglik is die d1-waarde op 2 sekondes vir die opvolgende ${ }^{13} \mathrm{C}$-analises ingestel. NOE opbouing ("Nuclear-Overhauser" oordrag van polarisasie van een stel kerne na 'n ander stel kerne) is onderdruk deur van die pulsprogram "zgig" gebruik te maak (die protonontkoppelaar is gedurende die opname, sowel as gedurende die ontspanningstyd aangeskakel) en het 'n SINO-waarde van 2.84 opgelewer. 'n Verdere poging om die opnametyd te verkort deur van pulse met 'n korter tydsduur gebruik te maak, is aangewend. Die P0-parameterwaarde (pulshoek) is na $2.33 \mu$ s verander en die gevolglike $23.3^{\circ}$ puls het 'n SINO-waarde van 4.46 opgelewer. Die spektra was egter as gevolg van 'n tekort aan genoegsame resolusie onbruikbaar. Meervoudige verfynings sou benodig word om die verlangde, eenduidige data op te lewer. Laastens is die TD-waarde vanaf 163840 na 8192 verander, maar het daartoe gelei dat 'n basislyn gevorm is wat onmoontlik geïntegreer kon word. Die ${ }^{13} \mathrm{C}$-parameterstel wat tydens hierdie ondersoek ontwikkel is, word in Tabel 3 saamgevat.

\begin{tabular}{ll} 
TABEL 3: & ${ }^{13}$ C-parameterstel. \\
\hline Offset [dpm] & 323.72900 \\
Pulproga & zgpg30 \\
TD & 163840 \\
d1 & 2.000 \\
NS & 15104 \\
DS & 4 \\
SW [dpm] & 345.0698 \\
AQ [s] & 1.7695220 \\
O1P [dpm] & 150.997
\end{tabular}

a Die ontkoppelaar is, soos tydens die ${ }^{31} \mathrm{P}$-analises, gedurende die opname aangeskakel. 


\section{${ }^{31}$ P-parameterstel}

Die verstekwaardes, soos in die Topspin 2.1 rekenaarprogrammatuur ingestel is, is tydens hierdie ondersoek gebruik; die ${ }^{31} \mathrm{P}$-parameterstel word in Tabel 4 saamgevat.

\begin{tabular}{ll} 
TABEL 4: & ${ }^{31}$ P-parameterstel. \\
\hline Offset [dpm] & 323.72900 \\
Pulproga & zgpg30 \\
TD & 163840 \\
d1 & 2.000 \\
NS & 15104 \\
DS & 4 \\
SW [dpm] & 345.0698 \\
AQ [s] & 1.7695220 \\
O1P [dpm] & 150.997 \\
\hline
\end{tabular}

a "pg" is die afkorting vir "power gated" (die ontkoppelaar is gedurende die opname aangeskakel) en is die pulsprogram wat vir roetine ${ }^{31} \mathrm{P}-\mathrm{KMR}$-analises gebruik word. Die pieke word as singulette, weens protonontkoppeling, aangedui.

b 'n Lae krag, breëband, heterokernige ontkoppelingsproses wat geskoei is op die gebruik van ' $n$ reeks saamgestelde radiofrekwensiepulse (waltz16 en mlev) van $90^{\circ}, 180^{\circ}$ en $270^{\circ}$, wat in 'n herhalende- of supersiklus uitgevoer word.

\section{DEPT135-parameterstel}

Die SW-parameterwaarde is vanaf 238.4 na $306.7 \mathrm{dpm}$ verander, om te verseker dat die karbeensein waargeneem kon word. Die TD0-parameterwaarde, wat die aantal herhalings wat deur die pulssiklus uitgevoer word bepaal, is vanaf 1 na 15 verander. 'n Enkele siklus neem 256 skanderings in beslag en gevolgik is 3840 skanderings uitgevoer indien die waarde op 15 gestel is. Die data is na elke 256 skanderings op die rekenaar se hardeskyf gestoor om sodoende die moontlike verlies van data tot ' $n$ minimum te beperk. Deur die opnametyd vanaf 0.911 tot 0.707 te verlaag, is die spektrumresolusie genoegsaam verbeter om eenduidige piekverskuiwings waar te neem. Die volledige DEPT135-parameterstel word in Tabel 5 weergegee.

TABEL 5: DEPT135-parameterste

\begin{tabular}{|c|c|c|}
\hline & Offset [dpm] & 304.57471 \\
\hline & Pulprog ${ }^{a}$ & dept135 \\
\hline & TD & 65536 \\
\hline & d1 [s] & 2.000 \\
\hline & NS & 256 \\
\hline & DS & 4 \\
\hline & $\mathrm{AQ}[\mathrm{s}]$ & 0.7078338 \\
\hline & J-pass filter ${ }^{b}$ & 145.00 \\
\hline \multicolumn{3}{|c|}{$\begin{array}{l}\text { Multiplisiteitsgeredigeerde }{ }^{13} \mathrm{C} \text {-spektra. } \\
\text { die koppelingskonstantedeurlatingsfilter verwyder vinnig-ontwikkelende } \\
\text { proton-koolstof spin-spin koppelingsfrekwensies ("spin-spin coupling } \\
\text { coherences"), m.a.w. slegs die frekwensies kleiner as die drempelwaarde van } \\
\text { die filter word vir die spektrum opgeneem. }\end{array}$} \\
\hline
\end{tabular}

\section{COSY-parameterstel}

Die SW-parameterwaarde is vanaf 13.35 na $20.55 \mathrm{dpm}$ verander. Die d1-parameterwaarde is vanaf 1.486 na 4.474 sekondes verleng om volledige ontspanning te verseker. Die COSY-parameterstel word in Tabel 6 opgesom.
TABEL 6: COSY-parameterstel.

\begin{tabular}{|c|c|c|c|}
\hline & $\mathrm{F} 2$ & & F1 \\
\hline Pulproga & & cosygpqf & \\
\hline TD & 2048 & & 128 \\
\hline $\mathrm{d} 1[\mathrm{~s}]$ & & 4.474 & \\
\hline NS & & 1 & \\
\hline DS & & 8 & \\
\hline $\mathrm{AQ}[\mathrm{s}]$ & 0.1278452 & & 0.0079875 \\
\hline
\end{tabular}

\section{HSQC-parameterstel}

DieSW-parameterwaarde van dieF2-direkte opnamekanaal asook die d1-parameterwaarde, is ooreenstemmend met die COSY-analise na onderskeidelik $20.55 \mathrm{dpm}$ en 4.474 sekondes verstel. Voorts is die SW-parameterwaarde van die F1-indirekte opnamekanaal vanaf 165.63 na 306.72 dpm verstel. Die HSQC-parameterstel word in Tabel 7 uiteengesit.

TABEL 7: HSQC-parameterstel.

\begin{tabular}{llll}
\hline & F2 & hsqcedetgp & \\
Pulproga & & & \\
TD & 1024 & 4.474 & 256 \\
d1 $[\mathrm{s}]$ & & 2 & \\
NS & & 16 & \\
DS & & & 0.0051202 \\
AQ [s] & 0.0639476 &
\end{tabular}

Fase sensitiewe 2D multiplisiteitsgeredigeerde HSQC-opname.

\section{HMBC-parameterstel}

Die parameterwaardeverstellings van die HSQC-analise is sonder wysiging na die HMBC-analise oorgedra. Die HMBC-parameterstel word in Tabel 8 opgesom.

TABEL 8: $\quad$ HMBC-parameterstel.

\begin{tabular}{llll}
\hline & F2 & hsqcedetgp & \\
Pulprog & & & \\
TD & & 4.474 & 128 \\
d1 $[\mathrm{s}]$ & 4096 & 8 & \\
NS & & 16 & \\
DS & & & 0.0019093 \\
AQ $[\mathrm{s}]$ & 0.2556404 & & \\
\hline
\end{tabular}

a Inverse waarnemings van proton-koolstof-langafstandskorrelasie met gradiëntpulsseleksie en geen ontkoppeling gedurende opname nie. Dit is 'n heterokernige analise.

\section{Herhaalbaarheid van KMR-analises}

Die KMR-analises is ten minste driemaal herhaal. Die eerste twee herhalings is met behulp van 'n $5 \mathrm{~mm}$ BBOpylstif opgeneem, gevolg deur 'n enkele opname met behulp van 'n 5 mm TBI-pylstif. Die TBI-pylstif is sodanig vervaardig dat die ${ }^{1} \mathrm{H}$-observasiewindings die naaste aan die KMR-buis geleë is. Die buitenste observasiewindings word gebruik om X-kerne oor die wydste moontlike radiofrekwensiegebied waar te neem. Die TBI-pylstif kan vir toekomstige ondersoeke van organometaalkomplekse gebruik word. 
Daar is twee nadele aan die pylstif verbonde. Eerstens moet handgedrewe radiofrekwensiepassing en -versterking van die pylstif uitgevoer word wat tot gevolg kon hê dat die resultate wisselvallig is weens onnoukeurige instelling van die pylstif. Tweedens, is die X-kernobservasiewindings verder vanaf die KMR-buis geleë. Laasgenoemde is nadelig vir die sensitiwiteit van opnames waarvoor kerne, insluitend koolstof, 'n lae natuurlike isotoopvoorkoms het. Die data wat hierdeur verkry is, is gedeeltelik bruikbaar. In die resonansiegebiede waar daar oorvleuelende pieke voorkom, soos in die aromatiese gebied, kon toekennings egter nie uitgevoer word nie. Die X-kernobservasiewindings van die BBO-pylstif is nader aan die KMR-buis geleë en vervolgens is meer bruikbare ${ }^{13} \mathrm{C}$-analiseresultate hiermee opgelewer. Die outomatiese radiofrekwensiepassing en -versterking het, in ooreenstemming met 'n soortgelyke ondersoek waartydens 'n $5 \mathrm{~mm}$ TXI-Z pylstif (Hendrickx et al., 2010) aangewend is, tot verbeterde resolusie tydens die KMR-analises gelei.

\section{Prekatalisatorpiekverskuiwingswaardetoe- kenning}

Die voorkoms van, hoofsaalik, molekulêre simmetrie het gelei tot die besluit om al die atome in die onderstaande strukture nie te numereer nie. Die simmetrie kan aan die voorkoms van chemiese- en magnetiese ekwivalensie van die prekatalisatore toegeskryf word.

\section{Grubbs-1-prekatalisator (1)}

Die genumereerde struktuur vir prekatalisator 1 word in Figuur 3 uitgebeeld. Schwab et al. (1996) het hierdie prekatalisator gesintetiseer en op 'n $500 \mathrm{MHz}$ KMR met $\mathrm{CD}_{2} \mathrm{Cl}_{2}$ as oplosmiddel geanaliseer en gekarakteriseer. Die KMR-parameterstel wat deur Schwab et al. (1996) gebruik is, is onbekend. ' $\mathrm{n}$ Vergelyking van die ${ }^{1} \mathrm{H}$ - en ${ }^{13} \mathrm{C}-\mathrm{KMR}$ waardes verkry, met die parameterstel wat tydens hierdie ondersoek ontwikkel is, word met die waardes van Schwab et al. (1996) in Tabel 9 uitgebeeld

Die ${ }^{31} \mathrm{P}$-sein wat by $35.7 \mathrm{dpm}$ tydens hierdie ondersoek waargeneem is, stem goed ooreen met diesein by $36.6 \mathrm{dpm}$ wat deur Schwab et al. (1996) gerapporteer is. Jordaan (2007) het

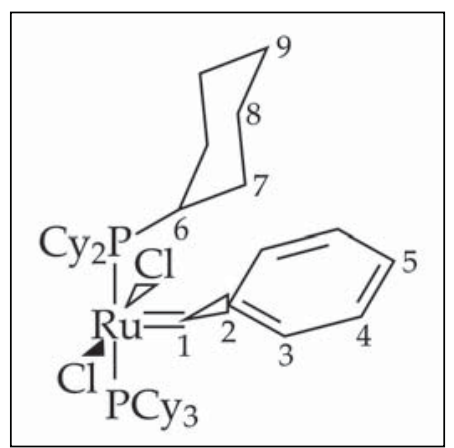

FIGUUR 3: Die genumereerde Grubbs-1-prekatalisator (1) struktuur.

die prekatalisator ondersoek en die $\mathrm{PCy}_{3}$-fosforsein by 35.63 dpm waargeneem. Die piekverskuiwingswaardetoekenning vir koolstowwe C7 en C8, verkry tydens hierdie ondersoek, verskil nie noemenswaardig van die waardes wat deur Schwab et al. (1996) gerapporteer is nie. Die toekenning van C7 is tydens die ondersoek met HMBC-korrelasie-analise bevestig. Die piekverskuiwingswaardetoekenning van koolstof C8 is deur die ooreenkoms tussen die waargenome en literatuurwaarde van koolstof C9 bekragtig. Hierdie piekverskuiwingswaardevergelyking bevestig dat die KMR-parameterstel, wat tydens die ondersoek ontwikkel is, geskik is om hierdie prekatalisator ten volle te karakteriseer.

\section{Grubbs-2-prekatalisator (2)}

Scholl et al. (1999) het die sintese en gedeeltelike ${ }^{1} \mathrm{H}-\mathrm{KMR}-$ karakterisering van prekatalisator 2 gerapporteer. Vervolgens het Gallagher et al. (2008) 'n lae-temperatuur KMRondersoek in $\mathrm{CDCl}_{3}$ as oplosmiddel uitgevoer. Volledige ${ }^{1} \mathrm{H}$-piekverskuiwingswaardes is deur Gallagher et al. (2008) gerapporteer. Die analises is op 'n laer-resolusie KMRspektrometer $(300 \mathrm{MHz})$ uitgevoer by lae temperature. Die gewense, hoër-resolusie spektra is hierdeur opgelewer. Die ${ }^{1} \mathrm{H}-\mathrm{KMR}$-piekverskuiwingswaardevergelyking van prekatalisator 2 word in Tabel 10 saamgevat. Die toegekende piekverskuiwingswaardes van Gallagher et al. (2008) vir die H4 en H5 protone verskil van die waardes wat tydens hierdie ondersoek gevind is. Die piekverskuiwingswaardes kon nie met behulp van die lae resolusie COSY-spektrum bekragtig word nie maar, die

TABEL 9: Vergelyking van die waargenome en literatuur (Schwab et al., 1996) gerapporteerde ${ }^{1} \mathrm{H}$ - en ${ }^{13}$ C-piekverskuiwingswaardes ${ }^{\mathrm{a}}$ van prekatalisator 1.

\begin{tabular}{|c|c|c|c|c|}
\hline Proton/ & Huidige ondersoek & Literatuur & Huidige ondersoek & Literatuur \\
\hline Koolstof & $\delta^{1} \mathrm{H}\left(\mathrm{J}_{\mathrm{H}} \text { in } \mathrm{Hz}\right)^{\mathrm{b}}$ & $\delta^{1} \mathrm{H}\left(\mathrm{J}_{\mathrm{H}}\right.$ in $\left.\mathrm{Hz}\right)$ & $\delta{ }^{13} \mathrm{C}(\mathrm{dpm})^{\mathrm{b}}$ & $\delta^{13} \mathrm{C}(\mathrm{dpm})$ \\
\hline 1 & $19.95 \mathrm{~s}$ & 20.02 & $294.2 \mathrm{D}$ & 294.7 \\
\hline 2 & - & - & $152.4 \mathrm{~S}$ & 153.1 \\
\hline 3 & $8.40(7.1) d$ & $8.44(7.6)$ & $130.7 \mathrm{D}$ & 131.2 \\
\hline 4 & $7.29(7.9) \mathrm{t}$ & - & $128.8 \mathrm{D}$ & 129.4 \\
\hline 5 & $7.50(7.35) \mathrm{t}$ & $7.33(7.6)$ & $129.0 \mathrm{D}$ & 129.7 \\
\hline 6 & $2.57 \mathrm{~s}$ & $2.62-2.58$ & $31.9 \mathrm{D}$ & 32.4 \\
\hline 7 & $1.63(11.7) \mathrm{d}$ & 1.77 & $29.5 \mathrm{~T}$ & 28.2 \\
\hline 8 & $1.36(12.2) \mathrm{k}$ & $1.46-1.39$ & $27.6 \mathrm{~T}$ & 30.0 \\
\hline 9 & $1.18 \mathrm{~m}$ & $1.25-1.16$ & $26.3 \mathrm{~T}$ & 26.9 \\
\hline
\end{tabular}

${ }^{1} \mathrm{H}$-Spektrum: $600 \mathrm{MHz},{ }^{13} \mathrm{C}$-Spektrum: $150 \mathrm{MHz}$, oplosmiddel $\mathrm{CDCl}_{3}$.

Multiplisiteit word as volg aangedui: hoofletters dui op direk gekoppelde protone aan koolstowwe en kleinletters dui op die multiplisiteit wat op die spektra waargeneem kon word. $\mathrm{S} / \mathrm{s}=$ singulet, $\mathrm{D} / \mathrm{d}=$ doeblet, $\mathrm{T} / \mathrm{t}=$ triplet, $\mathrm{k}=\mathrm{kwartet}, \mathrm{m}=$ multiplet. 
TABEL 10: Vergelyking van die eksperimentele en literatuur (Gallagher et al., 2008) gerapporteerde ${ }^{1} \mathrm{H}$-piekverskuiwingswaardes ${ }^{\mathrm{a}}$ van prekatalisator $\mathbf{2}$.

\begin{tabular}{|c|c|c|c|}
\hline Katalisator & Proton & $\begin{array}{l}\text { Huidige ondersoek } \\
\qquad \delta^{1} \mathrm{H}\left(\mathrm{J}_{\mathrm{H}} \text { in } \mathrm{Hz}\right)^{\mathrm{b}}\end{array}$ & $\begin{array}{c}\text { Literatuur } \\
\quad \delta^{1} \mathrm{H}\end{array}$ \\
\hline & 1 & $19.11 \mathrm{~s}$ & 19.16 \\
\hline & 3 & $6.99 \mathrm{~s}$ & 6.90 \\
\hline & 4 & $7.32(7.2) \mathrm{t}$ & 7.10 \\
\hline & 5 & $7.06 \mathrm{~s}$ & 7.40 \\
\hline & 7 & $3.78 \mathrm{~s}$ & - \\
\hline & 10 & $5.79 \mathrm{~s}$ & 6.28 \\
\hline & 12 & $1.88 \mathrm{~s}$ & 1.90 \\
\hline & 13 & $2.29 \mathrm{~s}$ & 2.28 \\
\hline & 14 & $2.17(11.2) \mathrm{k}$ & - \\
\hline & 15 & $0.77 \mathrm{~m}$ & - \\
\hline & 16 & $1.49 \mathrm{~m}$ & - \\
\hline & 17 & $0.97 \mathrm{~m}$ & - \\
\hline
\end{tabular}

${ }^{1} \mathrm{H}$-Spektrum: $600 \mathrm{MHz}$, oplosmiddel $\mathrm{CDCl}_{3}$.

Kleinletters dui op die multiplisiteit wat op die spektra waargeneem kon word. $\mathrm{s}=$ singulet, $\mathrm{t}=$ triplet, $\mathrm{k}=\mathrm{kwartet}, \mathrm{m}=$ multiplet.

HMBC-spektra het die toekennings bevestig. Scholl et al. (1999) het die fosforpiekverskuiwingswaarde van die $\mathrm{PCy}_{3}-$ ligand as 31,41 dpm gerapporteer, terwyl die verskuiwing as $28.92 \mathrm{dpm}$ deur Jordaan (2007) gerapporteer is. Die ondersoek van Scholl et al. (1999) vermeld nie of 'n verwysingstandaard tydens die KMR-analise gebruik is nie. Die verskil in die fosforpiekverskuiwingswaarde kan moontlik aan die oplosmiddel, $\mathrm{C}_{6} \mathrm{D}_{6}$, wat deur Scholl et al. (1999) gebruik is, toegeskryf word. Die $\mathrm{PCy}_{3}-$ fosforpiekverskuiwingswaarde van $29.04 \mathrm{dpm}$, wat tydens die hierdie ondersoek opgelewer is, stem goed ooreen met die waarde, wat deur Jordaan (2007) gerapporteer is. Prekatalisator $\mathbf{2}$ is, dienooreenkomstig met $\mathbf{1}$, ten volle met die KMR-parameterstel, wat tydens hierdie ondersoek ontwikkel is, gekarakteriseer.

\section{Grubbs-tipe-prekatalisator 3}

Die ${ }^{1} \mathrm{H}$ - en ${ }^{13} \mathrm{C}-\mathrm{KMR}$-piekverskuiwingswaardes van prekatalisator 3 (Figuur 4) word in Tabel 11 saamgevat. Die waargenome piekverskuiwingswaardes stem goed ooreen met die beperkte waardes wat deur Wilhelm et al. (1997) gerapporteer is. Die ${ }^{1} \mathrm{H}$-piekverskuiwingswaardes van die prekatalisator is feitlik volledig onderskei deur van die KMR-parameterstel wat tydens hierdie ondersoek ontwikkel is gebruik te maak. Die resolusie van die onder- skeie spektra was tydens analise onvoldoende om die metielkoolstofpiekverskuiwingswaardes van C4 en C5 vanaf koolstof C9 te onderskei. Die resolusie van die spektra kan moontlik in toekomstige ondersoeke verbeter word deur die spektraalwydte te vernou sodat net die alifatiese gebied beskou word.

Voorts kan ondersoek ingestel word na die aanwending van gevormde, adiabatiese pulsprogramme om die spektrumresolusie te verbeter. Die verbeterde resolusie sou moontlik die toekenning van hierdie koolstofpiekverskuiwingswaardes vergemaklik. Die $\mathrm{PCy}_{3}$-ligand se fosforpiekverskuiwingswaarde is tydens hierdie ondersoek

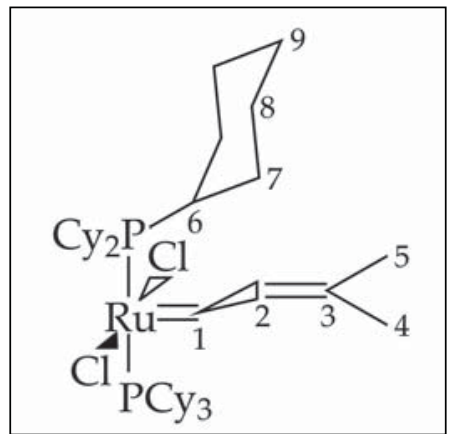

FIGUUR 4: Die genumereerde Grubbs-tipe-prekatalisator 3 struktuur.

TABEL 11: Die KMR-piekverskuiwingswaardes ${ }^{\mathrm{a}}$ van prekatalisator 3.

\begin{tabular}{|c|c|c|c|c|}
\hline Pronton/ & Huidige ondersoek & Literatuur & Huidige ondersoek & Literatuur \\
\hline & & & & \\
\hline 1 & $19.23(11.2) d$ & $19.26(11.7) \mathrm{d}$ & $288.0 \mathrm{D}$ & $288.4 \mathrm{D}$ \\
\hline 2 & $7.88(11.3) d$ & $7.81(11.7) \mathrm{d}$ & $146.6 \mathrm{D}$ & $146.9 \mathrm{D}$ \\
\hline 3 & - & - & $133.7 \mathrm{~S}$ & $133.5 \mathrm{~S}$ \\
\hline 4 & $1.50 \mathrm{k}(12.4) / 1.25 \mathrm{~m}^{\mathrm{c}}$ & - & $20.2 / 27.7 / 28.7 \mathrm{~T}^{\mathrm{d}}$ & - \\
\hline 5 & $1.50 \mathrm{k}(12.4) / 1.25 \mathrm{~m}^{\mathrm{c}}$ & - & $20.2 / 27.7 / 28.7 \mathrm{~T}^{\mathrm{d}}$ & - \\
\hline 6 & $2.52 \mathrm{~s}$ & - & $31.7 \mathrm{D}$ & - \\
\hline 7 & $1.42(11.9) \mathrm{k}$ & - & $29.4 \mathrm{~T}$ & - \\
\hline 8 & $1.65(9.4) d$ & - & $26.4 \mathrm{~T}$ & - \\
\hline 9 & $1.20 \mathrm{~m}$ & - & $20.2 / 27.7 / 28.7 \mathrm{~T}^{\mathrm{d}}$ & - \\
\hline
\end{tabular}

${ }^{1} \mathrm{H}$-Spektrum: $600 \mathrm{MHz},{ }^{13} \mathrm{C}$-Spektrum: $150 \mathrm{MHz}$, oplosmiddel $\mathrm{CDCl}_{3}$.

b Multiplisiteit word as volg aangedui: hoofletters dui op direk gekoppelde protone aan koolstowwe en kleinletters dui op die multiplisiteit wat op die spektra waargeneem kon word. $\mathrm{S} / \mathrm{s}=$ singulet, $\mathrm{D} / \mathrm{d}=$ doeblet, $\mathrm{T} / \mathrm{t}=$ triplet, $\mathrm{k}=\mathrm{kwartet}$.

Protone kon nie onderskei of toegeken word nie

d Koolstowwe kon nie onderskei of toegeken word nie. 
by $24.08 \mathrm{dpm}$ waargeneem. Dit is teenstrydig met die 31.41 dpm-waarde wat deur Wilhelm et al. (1997) gerapporteer is. Die gebruik van 'n verwysingstandaard tydens die KMRanalise deur Wilhelm et al. (1997), wat as verklaring van die verskil kan dien, word nie vermeld nie. Die karakterisering van die struktuur van prekatalisator 3 is noemenswaardig met die ontwikkelde KMR-parameterstel verbeter.

\section{Grubbs-tipe-prekatalisator 4}

Die $\mathrm{PCy}_{3}$-ligand se fosforpiekverskuiwingswaarde vir 4 is deur Jordaan (2007) by $41.5 \mathrm{dpm}$ en deur Denk et al. (2002) by $49.8 \mathrm{dpm}$ waargeneem. Tydens hierdie ondersoek is egter gevind dat die piek by $40.26 \mathrm{dpm}$ voorkom. Die piekverskuiwingswaarde van die geoksideerde fosfienligand, $\mathrm{OPCy}_{3}$, is tydens die ondersoek by $50.3 \mathrm{dpm}$ waargeneem. Die moontlikheid dat Denk et al. (2002) die $\mathrm{OPC}_{3}$ ligand waargeneem het, kan as verklaring vir die verskil in die waargenome fosforpiekverskuiwingswaardes dien. Die ${ }^{1} \mathrm{H}-\mathrm{KMR}$ piekverskuiwingswaarde vergelyking van prekatalisator 4 word in Tabel 12 saamgevat.
Die piekverskuiwingswaarde vir $\mathrm{H} 1$ stem met die gerapporteerde literatuurwaardes ooreen. Die toekenning van piekverskuiwingswaardes vir $\mathrm{H} 15$ tot $\mathrm{H} 18$ en $\mathrm{C} 15$ tot $\mathrm{C} 18$ in die 0 tot $3 \mathrm{dpm}$ gebied op onderskeidelik die ${ }^{1} \mathrm{H}$-spektrum en in die 20 tot $50 \mathrm{dpm}$ gebied op die ${ }^{13} \mathrm{C}$-spekrum, is deur die lae piekresolusie in die COSYen HSQC-spektra belemmer. Daar is wel voldoende HSQC- en HMBC-spektrumresolusie waargeneem om sodoende die piekverskuiwingswaardes vir $\mathrm{H} 11$ tot $\mathrm{H} 13$ te bevestig. Die tekort aan HSQC- of HMBC-analise in die literatuurondersoeke mag die verskil tussen die piekverskuiwingswaardes verklaar. Die toekenning van piekverskuiwingswaardes van prekatalisator 4 is met dié KMR-parameterstel verbeter. Ruimte bestaan vir verfyning in toekomstige ondersoeke om die absolute toekenning van al die piekverskuiwingswaardes te verbeter.

\section{Grubbs-tipe-prekatalisator 5}

Die ${ }^{1} \mathrm{H}-\mathrm{KMR}$ piekverskuiwingswaarde vergelyking van prekatalisator $\mathbf{5}$ word in Tabel 13 saamgevat.

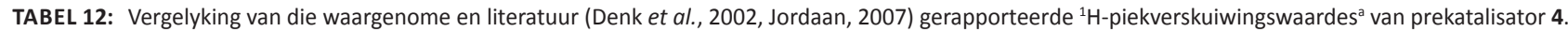

\begin{tabular}{|c|c|c|c|c|}
\hline Katalisator & Proton & $\begin{array}{l}\text { Huidige ondersoek } \\
\qquad \delta^{1}{ }^{1}\left(J_{H} \text { in } \mathrm{Hz}\right)^{b}\end{array}$ & $\begin{array}{l}\text { Literatuur } \\
\qquad \delta^{1} \mathrm{H}\end{array}$ & $\begin{array}{l}\text { Literatuur } \\
\qquad \delta^{1} \mathrm{H}\end{array}$ \\
\hline & 1 & $17.75(17.1) d$ & 17.85 & 17.30 \\
\hline & 3 & $7.02(7.2) t^{c}$ & 7.08 & - \\
\hline & 4 & $6.96(7.1) t^{c}$ & 6.96 & 7.25 \\
\hline & 5 & $7.43(7.1) t^{c}$ & 7.38 & 7.71 \\
\hline & 6 & $2.35(12.2) \mathrm{k}$ & - & 2.44 \\
\hline & 7 & $1.78 \mathrm{~m}$ & - & $2.44-0.85$ \\
\hline & 8 & $2.09(15.2) \mathrm{t}$ & - & $2.44-0.85$ \\
\hline & 9 & $1.26 \mathrm{~m}$ & - & $2.44-0.85$ \\
\hline & 10 & $9.04 \mathrm{~s}$ & 8.95 & 9.14 \\
\hline & 11 & $6.95(7.1) t^{c}$ & 6.90 & - \\
\hline & 12 & $7.43(7.1) \mathrm{t}$ & 6.96 & - \\
\hline & 13 & $7.22(7.1) \mathrm{t}$ & 7.02 & - \\
\hline
\end{tabular}

${ }^{1} \mathrm{H}$-Spektrum: $600 \mathrm{MHz}$, oplosmiddel $\mathrm{CDCl}_{3}$.

Kleinletters dui op die multiplisiteit wat op die spektra waargeneem kon word. $s=$ singulet, $d=$ doeblet, $t=$ triplet, $k=k$ wartet, $m=$ multiplet.

Protone kon nie onderskei of toegeken word nie.

TABEL 13: Vergelyking van die waargenome en literatuur (Jordaan, 2007) gerapporteerde ${ }^{1} \mathrm{H}$-piekverskuiwingswaardes ${ }^{\mathrm{a}}$ van prekatalisator 5.

\begin{tabular}{|c|c|c|c|}
\hline Katalisator & Proton & $\begin{array}{l}\text { Huidige ondersoek } \\
\qquad \delta^{1} \mathrm{H}\left(\mathrm{J}_{\mathrm{H}} \text { in } \mathrm{Hz}\right)^{\mathrm{b}}\end{array}$ & $\begin{array}{c}\text { Literatuur } \\
\quad \delta^{1} \mathrm{H}\end{array}$ \\
\hline & 1 & $18.00 \mathrm{~s}$ & 17.96 \\
\hline & 3 & $6.93 \mathrm{~d}$ & 7.24 \\
\hline & 4 & $7.34(7.7) \mathrm{d}$ & 6.88 \\
\hline & 5 & $7.67(7.7) \mathrm{t}$ & $7.04-7.15$ \\
\hline & 7 & $3.98 \mathrm{~m}$ & 3.85 \\
\hline & 10 & $6.71 \mathrm{~s}$ & $6.66 / 6.88$ \\
\hline & 12 & $2.59 / 2.42 / 2.59 \mathrm{~s}^{\mathrm{c}}$ & 2.15 \\
\hline & 13 & $2.59 / 2.42 / 2.59 \mathrm{~s}^{\mathrm{c}}$ & $2.40 / 2.55$ \\
\hline & 14 & $9.45(5.4) d$ & 9.55 \\
\hline & 15 & $6.85(6.3) \mathrm{t}$ & 6.78 \\
\hline 22 & 16 & $7.17 \mathrm{~m}$ & $7.04-7.15$ \\
\hline & 17 & $8.49(4.5) d$ & 6.60 \\
\hline & 20 & 1.66 & 1.25 \\
\hline & 21 & 1.07 & 1.45 \\
\hline & 22 & $1.83-0.86^{c}$ & 1.65 \\
\hline
\end{tabular}

${ }^{1} \mathrm{H}$-Spektrum: $600 \mathrm{MHz}$, oplosmiddel $\mathrm{CDCl}_{3}$.

Kleinletters dui op die multiplisiteit wat op die spektra waargeneem kon word. $\mathrm{s}=$ singulet, $\mathrm{d}=$ doeblet, $\mathrm{t}=$ triplet, $\mathrm{m}=$ multiplet.

Protone kon nie onderskei of toegeken word nie. 
Die waarneming van onvoldoende resolusie in die COSYen HSQC-spektra het die moontlikheid van absolute piekverskuiwingswaardetoekenning van die kerne in 5 belemmer. Die KMR-parameterstel was egter voldoende om die toekenning van die piekverskuiwingswaardes van 5 in enkele gevalle te verbeter. Die noodsaak om die parameterstel in toekomstige ondersoeke verder te verfyn word weer duidelik.

\section{Grubbs-tipe-prekatalisator 6}

Die ${ }^{1} \mathrm{H}-\mathrm{KMR}$ piekverskuiwingswaardes van prekatalisator 6 in Tabel 14 vertoon variasie in vergelyking met die literatuurwaardes (Jordaan, 2007). Die voorkoms van onvoldoende resolusie asook oorvleuelende pieke in verskeie van die spektra het die toekenning van die piekverskuiwingswaardes, soos tydens die analise van die spektra van 4 en 5 ook waargeneem is, verhoed. Die analise van 6 se KMR-spektra bekragtig weer die noodsaaklikheid om die KMR-parameterstel in toekomstige ondersoeke van die piridinielalkoholatoprekatalisatore verder te verfyn.

\section{Grubbs-tipe-prekatalisator 7}

Die toegekende ${ }^{1} \mathrm{H}-\mathrm{KMR}$-piekverskuiwingswaardes van prekatalisator $\mathbf{7}$ (Tabel 15) verskil van die literatuurwaardes (Jordaan, 2007). Die voorkoms van onvoldoende resolusie in verskeie spektra het weereens absolute toekenning van al die piekverskuiwingswaardes belemmer. Karbeenpiekverskuiwingswaardes van H1 (17.39 dpm) en C1 (262.1 $\mathrm{dpm}$ ) is deur Schachner et al. (2011) vermeld. Daarenteen het die huidige ondersoek waardes van onderskeidelik $17.10 \mathrm{dpm}$ en $290.5 \mathrm{dpm}$ getoon. Die opname van die KMRspektra in benseen $\left(\mathrm{C}_{6} \mathrm{D}_{6}\right)$ in teenstelling met chloroform wat tydens hierdie ondersoek gebruik is, mag hierdie verskille moontlik verklaar. Die ruimte vir verdere verfyning van die KMR-parameterstel in toekomstige ondersoeke word dus weer benadruk.

\section{Grubbs-tipe-prekatalisator 8}

Die ${ }^{1} \mathrm{H}$ - en ${ }^{13} \mathrm{C}-\mathrm{KMR}$-piekverskuiwingswaardes van die nuut gesintetiseerde prekatalisator $\mathbf{8}$ word in Tabel 16

TABEL 14: Vergelyking van die waargenome en literatuur (Jordaan, 2007) gerapporteerde ${ }^{1} \mathrm{H}$-piekverskuiwingswaardes ${ }^{\mathrm{a}}$ van prekatalisator 6.

\begin{tabular}{|c|c|c|c|}
\hline Katalisator & Proton & $\begin{array}{l}\text { Huidige ondersoek } \\
\qquad \delta^{1} \mathrm{H}\left(\mathrm{J}_{\mathrm{H}} \text { in } \mathrm{Hz}\right)^{\mathrm{b}}\end{array}$ & $\begin{array}{l}\text { Literatuur } \\
\qquad \delta^{1} \mathrm{H}\end{array}$ \\
\hline & 1 & $17.58(17.4) d$ & 17.63 \\
\hline & 3 & $7.08(7.5) d$ & 6.54 \\
\hline & 4 & $6.50(7.5) d$ & 7.01 \\
\hline & 5 & $6.96-7.33^{c}$ & 7.20 \\
\hline & 10 & $9.60 \mathrm{~s}$ & 9.61 \\
\hline & 11 & $7.10 \mathrm{~m}$ & 7.14 \\
\hline & 12 & $6.74(7.6) d$ & 7.34 \\
\hline & 13 & $7.31 \mathrm{~m}$ & 6.78 \\
\hline & 17 & $6.96 \mathrm{~m}$ & $7.10 / 7.27$ \\
\hline & 18 & $6.96-7.33^{c}$ & $7.01 / 7.27$ \\
\hline & 19 & $6.96-7.33^{c}$ & 7.34 \\
\hline
\end{tabular}

${ }^{1} \mathrm{H}$-Spektrum: $600 \mathrm{MHz}$, oplosmiddel $\mathrm{CDCl}_{3}$.

Kleinletters dui op die multiplisiteit wat op die spektra waargeneem kon word. $s=$ singulet, $d=$ doeblet, $m=$ multiplet.

Protone kon nie onderskei of toegeken word nie.

TABEL 15: Vergelyking van die waargenome en literatuur (Jordaan, 2007) gerapporteerde ${ }^{1} \mathrm{H}$-piekverskuiwingswaardes ${ }^{\mathrm{a}}$ van prekatalisator 7.

\begin{tabular}{|c|c|c|c|}
\hline Katalisator & Proton & $\begin{array}{l}\text { Huidige ondersoek } \\
\qquad \delta^{1} \mathrm{H}\left(\mathrm{J}_{\mathrm{H}} \text { in } \mathrm{Hz}\right)^{\mathrm{b}}\end{array}$ & $\begin{array}{c}\text { Literatuur } \\
\delta^{1} \mathrm{H}\end{array}$ \\
\hline & 1 & $17.10 \mathrm{~s}$ & 17.18 \\
\hline & 3 & $6.73(7.5) \mathrm{t}$ & 6.43 \\
\hline & 4 & $7.02 t$ & 6.77 \\
\hline & 5 & $6.64 \mathrm{~s}$ & 7.19 \\
\hline & 7 & $4.00 \mathrm{~m}$ & 4.05 \\
\hline & 10 & $6.96 / 7.13 \mathrm{~m}^{c}$ & $6.71 / 6.98$ \\
\hline & 12 & $2.19 / 2.61 \mathrm{~s}^{c}$ & 2.20 \\
\hline & 13 & $2.19 / 2.61 \mathrm{~s}^{c}$ & $2.30 / 2.65$ \\
\hline & 14 & $9.60(5.3) d$ & 9.67 \\
\hline & 15 & $6.90 \mathrm{~m}$ & 7.03 \\
\hline & 16 & $6.36(7.6) d$ & 7.19 \\
\hline & 17 & $7.15 \mathrm{~m}$ & 6.64 \\
\hline & 21 & $6.96 \mathrm{~m}$ & $7.12-7.19$ \\
\hline & 22 & $6.58-7.34^{c}$ & $7.12-7.19$ \\
\hline & 23 & $6.58-7.34^{c}$ & $7.12-7.19$ \\
\hline
\end{tabular}


saamgevat. Die $\mathrm{PCy}_{3}$-fosforpiekverskuiwing is by 42.58 $\mathrm{dpm}$ en $38.66 \mathrm{dpm}$ waargeneem en die $\mathrm{OPCy}_{3}$-piek is by $50.06 \mathrm{dpm}$ uitgewys.

Verdere KMR-analise het op die teenwoordigheid van verskeie onskeibare isomere gedui. Die absolute toekenning van die KMR-piekverskuiwingswaardes is hierdeur belemmer. 'n Lae produkopbrengs (0.28 g, 33\%) tydens die sintese van 8 het daartoe gelei dat, byvoorbeeld, die DEPT90-analise om die piekverskuiwingswaarde van die C20 metielgroep toe te ken, nie uitgevoer is nie.
Die geskiktheid van die KMR-parameterstel vir die absolute karakterisering van hierdie prekatalisator kan nie eenduidig bepaal word totdat 'n verbeterde isolasiemetode vir hierdie prekatalisator ontwikkel is nie.

\section{Grubbs-tipe-prekatalisator 9}

Die ${ }^{1} \mathrm{H}-\mathrm{KMR}$-piekverskuiwingswaardes van prekatalisator 9 wat in Tabel 17 saamgevat is vertoon gedeeltelike oorstemming met die waardes wat deur Huijsmans (2009) gevind is.

TABEL 16: Die ${ }^{1} \mathrm{H}$ - en ${ }^{13} \mathrm{C}$-piekverskuiwingswaardes ${ }^{\mathrm{a}}$ van prekatalisator 8

\begin{tabular}{|c|c|c|c|c|}
\hline Katalisator & $\begin{array}{l}\text { Proton/ } \\
\text { Koolstof }\end{array}$ & $\delta^{1} \mathrm{H}(\mathrm{dpm})^{\mathrm{b}}$ & $\mathrm{J}_{\mathrm{H}}(\mathrm{Hz})$ & $\delta^{13} \mathrm{C}(\mathrm{dpm})^{\mathrm{b}}$ \\
\hline & 1 & $17.34 / 17.74 \mathrm{~d}$ & $17.7 / 17.2$ & $276.3 / 279.9 \mathrm{D}$ \\
\hline & 2 & - & - & $153.9 / 154.1 \mathrm{~S}$ \\
\hline & 3 & $6.91 \mathrm{t} / 7.16 \mathrm{~m}$ & 7.2 & $126.5 / 131.5 \mathrm{D}$ \\
\hline & 4 & $6.53 \mathrm{t}$ & 7.2 & $121.0-148.6^{d}$ \\
\hline & 5 & $6.30-7.90^{c}$ & - & $121.0-148.6^{d}$ \\
\hline & 6 & $1.23 \mathrm{~s}$ & - & $27.7 / 28.9 \mathrm{D}$ \\
\hline & 7 & $0.84-2.32^{c}$ & - & $21.7-35.0^{d}$ \\
\hline & 8 & $0.84-2.32^{c}$ & - & $21.7-35.0^{d}$ \\
\hline & 9 & $0.84-2.32^{c}$ & - & $21.7-35.0^{d}$ \\
\hline & 10 & $9.51 \mathrm{~s} / 9.66 \mathrm{~s}$ & - & $150.6 / 150.8 \mathrm{D}$ \\
\hline & 11 & $6.30-7.90^{c}$ & - & $121.0-148.6 \mathrm{~d}$ \\
\hline & 12 & $6.30-7.90^{c}$ & - & $121.0-148.6 \mathrm{~d}$ \\
\hline & 13 & $6.30-7.90^{c}$ & - & $121.0-148.6 \mathrm{~d}$ \\
\hline & 14 & - & - & $172.2 / 172.5 \mathrm{~S}$ \\
\hline & 15 & - & - & $96.5 / 97.5 \mathrm{~S}$ \\
\hline & 16 & - & - & $121.0-148.6^{d}$ \\
\hline & 17 & $6.30-7.90^{c}$ & - & $121.0-148.6^{d}$ \\
\hline & 18 & $6.30-7.90^{c}$ & - & $121.0-148.6^{d}$ \\
\hline & 19 & $6.30-7.90^{c}$ & - & $121.0-148.6^{d}$ \\
\hline & 20 & - & - & $121.0-148.6^{d}$ \\
\hline & 21 & $6.30-7.90^{c}$ & - & $121.0-148.6^{d}$ \\
\hline & 22 & $6.30-7.90^{c}$ & - & $121.0-148.6^{d}$ \\
\hline & 23 & $6.30-7.90^{c}$ & - & $121.0-148.6^{d}$ \\
\hline & 24 & $6.30-7.90^{c}$ & - & $131.5 / 132.0 \mathrm{~S}$ \\
\hline & 25 & - & - & $138.4 / 138.6 \mathrm{~S}$ \\
\hline & 26 & $0.84-2.32^{c}$ & - & $21.7-35.0^{d}$ \\
\hline
\end{tabular}

${ }^{1} \mathrm{H}$-Spektrum: $600 \mathrm{MHz},{ }^{13} \mathrm{C}$-Spektrum: $150 \mathrm{MHz}$, oplosmiddel $\mathrm{CDCl}_{3}$.

Multiplisiteit word as volg aangedui: hoofletters dui op direk gekoppelde protone aan koolstowwe en kleinletters dui op die multiplisiteit wat op die spektra waargeneem kon word. $\mathrm{S} / \mathrm{s}=$ singulet, $\mathrm{D} / \mathrm{d}=$ doeblet, $\mathrm{t}=$ triplet, $\mathrm{m}=$ multiplet

Protone kon nie onderskei of toegeken word nie.

Koolstowwe kon nie onderskei of toegeken word nie.

TABEL 17: Vergelyking van die waargenome en literatuur (Huijsmans, 2009) gerapporteerde ${ }^{1} \mathrm{H}_{\text {-piekverskuiwingswaardes }}{ }^{\mathrm{a}}$ van prekatalisator 9.

Katalisator

${ }^{1} \mathrm{H}$-Spektrum: $600 \mathrm{MHz}$, oplosmiddel $\mathrm{CDCl}_{3}$

Kleinletters dui op die multiplisiteit wat op die spektra waargeneem kon word. $\mathrm{s}=$ singulet, $\mathrm{d}=$ doeblet, $\mathrm{t}=$ triplet, $\mathrm{m}=$ multiplet.

Protone kon nie onderskei of toegeken word nie. 
Die voorkoms van onskeibare isomere in die geïsoleerde produk is ook tydens die KMR-analise geïdentifiseer. Die opname van DEPT90-spektra kan moontlik die toekenning van die metielkoolstof C30 se piekverskuiwingswaarde vergemaklik. Die KMR-parameterstel wat tydens hierdie ondersoek ontwikkel is, kan slegs regverdig vir hierdie prekatalisator geëvalueer word indien 'n verbeterde isolasie metode ontwikkel is.

\section{Gevolgtrekking}

Gedurende hierdie ondersoek is 'n KMR-parameterstel ontwikkel wat gebruik is om 'n reeks kommersiële en niekommersiële prekatalisatore te analiseer. Die resolusie van die ${ }^{1} \mathrm{H}-,{ }^{13} \mathrm{C}-,{ }^{31} \mathrm{P}-$, DEPT135- en HMBC-KMR-spektra van die kommersiëleprekatalisatore 1,2 en 3 was genoegsaamom die waargenome piekverskuiwingswaardes aan die onderskeie kerne toe te ken. Die KMR-karakterisering van die niekommersiële piridinielalkoholatoprekatalisatore 4 tot $\mathbf{9}$ is, in vergelyking met die literatuurpiekverskuiwingswaardes, verbeter. 'n Tekortkoming is egter geïdentifiseer ten opsigte van die lae resolusie van verskeie van die KMR-spektra, veral die nie-kommersiële prekatalisatore. Die absolute karakterisering van die kerne van die prekatalisatore is dus hierdeur belemmer. Dit word dus voorgestel dat die afgeleide KMR-parameterstel wat tydens die ondersoek ontwikkel is, verfyn moet word. Die noodsaaklikheid van verfyning vir die struktuuropklaring sou waarskynlik meer lig op die meganisme van die metatesereaksie kon werp. Indien onvoldoende resolusie op die spektra waargeneem word, mag die meganistiese ondersoeke belemmer of selfs verhoed word.

Verskeie voorstelle om die KMR-spektra se resolusie te verbeter kan oorweeg word. Die resolusie van die COSYKMR-spektra opname kan moontlik verbeter word deur die aantal herhalende siklusse van skanderings (TD0) vanaf een na vier te verhoog. In toekomstige ondersoeke kan die invloed van die DQF-pulsprogram op die resolusie van die COSY-opnames met die GPQF-pulsprogram vergelyk word. Die DQF-pulsprogram sou moontlike langafstand COSY-koppelinge verskuil teenoor die GPQF waar hierdie koppelinge steeds waargeneem sou kon word. Die invloed op die resolusie van die HSQC-spektra opname kan ondersoek word deur die spektraalwydte tot slegs die alifatiese of die aromatiese gebied op die spektrum te beperk. Die spektra opnametydsduur kan ook verkort word deur die TD-waarde vanaf 1024 na 512 te verander wat die aantal siklusse van herhalende skanderings (TD0) tot twee sal beperk. Koppelingskonstanstefilters ("J-pass filters") kan ook geoptimeer word om korten langafstandkoppelinge te onderskei. Verder kan artefakte in homo- en heterokernige koppeling (COSYen HSQC- of HMBC-spektra onderskeidelik) sowel as protonontkoppelde spektrumopnames, byvoorbeeld DEPT-spektra ook deur die koppelingskonstantefilters uitgeskakel word.
Die opname van DEPT90-spektra kan tesame met DEPT135-spektra gebruik word om die onderskeid tussen die metien- en metielkoolstofpiekverskuiwingswaardes te verbeter. Die resolusie van die DEPT90-spektra kan moontlik verbeter word deur, soos vir die COSY-spektra voorgestel is, die spektraalwydte tot onderskeidelik 0-60 dpm vir alifatiese kerne te beperk. Soortgelyk kan die spektraalwydte tot 100-150 dpm beperk word sodat slegs die aromatiese kerne ondersoek word.

Verder word die aanwending of ontwikkeling van gevormde, adiabatiese pulsprogramme aanbeveel. Hierdie pulse kan die volledige ontspanning van alle kerne toelaat wat tot 'n hoër sein-tot-geraasverhouding (SINO) in die opnames lei. Voorts sou die aanwending van gevormde, adiabatiese pulse verbeterde resolusie van oorvleuelende multiplette teweegbring.

Die waarneming is gemaak dat die oplosmiddelpiek op verskeie van die spektra, in vergelyking met die analietpieke, oorheersend voorkom. Die moontlikheid van oplosmiddelpiekonderdrukking deur middel van 'n selektiewe voorversadigingspulsprogram word in toekomstige studies voorgestel.

Hendrickx et al. (2010) het, aanvullend tot die spektra wat in hierdie ondersoek geanaliseer is, TOCSY-, ROESYen HSQC-TOCSY-spektra tydens die karakterisering van 'n reeks Grubbs-tipe-prekatalisatore opgeneem. Die HSQC-TOCSY-spektrum is ' $n$ 3D-opname waarin totale protonkorrelasies (TOCSY) gekombineer word met HSQC ( ${ }^{1} \mathrm{H}$ - en ${ }^{13} \mathrm{C}$-korrelasies) wat beduidend tot die toekenning van die piekverskuiwingswaardes van die kerne kan bydra. Die herhaling van Hendrickx et al. (2010) se KMR-analises is, soos feitlik al die vorige ondersoeke, deur 'n tekort aan 'n gerapporteerde KMR-parameterstel bemoeilik. Hierdie loodsondersoek het betekenisvolle waarde toegevoeg deur'n KMR-parameterstel te ontwikkel wat die toekenning van die piekverskuiwingswaardes aan die onderskeie kerne van die Grubbs-tipe-prekatalisatore te verbeter. Die noodsaaklikheid van verdere verfyning van die KMR-parameterstel in toekomstige ondersoeke word egter benadruk om te verseker dat die Grubbs-tipeprekatalisatore ten volle met behulp van KMR-analises gekarakteriseer kan word.

\section{Erkenning}

Ons bedank die Noordwes-Universiteit, die NNS en die CRB vir hul finansiële bydrae tot die studies van C de Lange. Ons bedank ook die Suid-Afrikaanse Akademie vir Wetenskap en Kuns vir hul finansiële bydrae tot die studies van F Marx. Ons bedank die Noordwes-Universiteit vir die gebruik van hul laboratoria. Ons wil ook graag mnr A Joubert bedank vir raad en inset tydens die KMR-analises asook Dr J Jordaan vir die MS-analises. 


\section{Mededingende belange}

Die outeurs verklaar geen konflik van belange nie.

\section{Outeursbydrae}

J.H.L.J. (Noordwes-Universiteit), C.d.L. (Noordwes-Universiteit) en H.C.M.V. (Noordwes-Universiteit) was vir die ontwerp van die projek en eksperimente verantwoordelik. C.d.L. het al die eksperimentele werk onder leiding van J.H.L.J. en H.C.M.V. uitgevoer. F.T.I.M. (Noordwes-Universiteit) en D.P.O. (Noordwes-Universiteit) was verantwoordelik vir die manuskrip konseptualisering en voorbereiding, met hersiening en redigering deur H.C.M.V.

\section{Verwysings}

Denk K, Fridgen J, Herrmann WA. 2002. N-Heterocyclic Carbenes, Part 33. Combining stable NHC and Chelating Pyridinyl-Alcoholato ligands: A Ruthenium catalys for applications at elevated temperatures. Advanced Synthesis \& Catalysis, 344, 666-670.

Gallagher MM, Rooney AD, Rooney JJ. 2008. Variable temperature 1H NMR studies on Grubbs catalysts. Journal of Organometallic Chemistry, 693, 1252-1260.

Grey RA. 2000. The 2000 Benjamin Franklin Medal in Chemistry presented to Rober H Grubbs. Journal of the Franklin Institute, 337, 793-805.

Hendrickx PMS, Drozdzak R, Verpoort F, Martins JC. 2010. Assignment and conformational investgation of asymmetric phenylindenylidene ruthenium complexes bearing N,O-bidentate ligands. Magnetic Resonance in Chemistry, $48,443-449$.

Herrmann WA, Haider JJ, Fridgen J, Lobmaier GM, Spiegler M. 2000. Chiral molybdenum(VI) and tungsten(VI) 2'-pyridinyl alcoholate complexes. Synthesis, structure and catalytic properties in asymmetric olefin epoxidation. Journal of Organometallic Chemistry, 603, 69-79.
Herrmann WA, Lobmaier GM, Priermeier T, Matiner MR, Scharbert B. 1997. New dioxomolybdenum(VI) catalysts for the selective oxidation of terminal n-alkenes with molecular oxygen. Journal of Molecular Catalysis A: Chemical, 117, 455-469.

Huijsmans CAA. 2009. Modelling and synthesis of Grubbs-type complexes with hemilabile ligands. M.Sc.-verhandeling, Noordwes-Universiteit.

Jordaan M. 2007. Experimental and theoretical investigation of new Grubbstype catalysts for the metathesis of alkenes. Ph.D.-proefskrif, NoordwesUniversiteit.

Ledoux N. 2007. Ruthenium olefin metathesis catalysts: tuning of the ligand environment $\mathrm{Ph}$. D-tesis, Ghent Universiteit.

Louie J, Grubbs RH. 2002. Metathesis of electron-rich olefins: Structure and reactivity of electron-rich carbene complexes. Organometallics, 21, 21532164

Macomber RS. 1997. A complete introduction to modern NMR spectroscopy, New York, John Wiley \& Sons Inc.

Mainz VV. 2004. Basic NMR concepts: A guide for the modern laboratory. Illinois: University of Illinois.

Rouhi M. 2005. Olefin metathesis gets Nobel nod. Chemical \& Engineering News Archive, 83, 8.

Schachner JA, Cabrera J, Padilla R, Fischer C, Van Der Schaaf PA, Pretot R, Rominger F, Limbach M. 2011. A set of olefin metathesis catalysts with extraordinary stickiness to silica. ACS Catalysis, 1, 872-876.

Scholl M, Ding S, Lee CW, Grubbs RH. 1999. Synthesis and activity of a new generation of Ruthenium-based olefin metathesis catalysts coordinated with 1,3-Dimesityl-4,5-dihydroimidazol-2-ylidene Ligands. Organic Letters, 1, 953956.

Schwab P, Grubbs RH, Ziller JW. 1996. Synthesis and applications of RuCl2(=CHR') (PR3)2: The influence of the alkylidene moiety on metathesis activity. Journal of the American Chemical Society, 118, 100-110.

Van Der Schaaf PA, Müehlebach A, Hafner A, Kolly R. 1999. Heterocyclyl ligand containing ruthenium and osmium catalysts. W09929701 (A1).

Wilhelm TE, Belderrain TR, Brown SN, Grubbs RH. 1997. Reactivity of Ru(H)(H2) $\mathrm{Cl}(\mathrm{PCy} 3) 2$ with propargyl and vinyl chlorides: new methodology to give metathesis-active Ruthenium carbenes. Organometallics, 16, 3867-3869. 